\title{
O PLANEJAMENTO MUNICIPAL INTEGRAL COMO CONTRIBUTO À MUDANÇA PARADIGMÁTICA DA POLÍTICA URBANA NO BRASIL
}

Integral municipal planning as a contribution to the paradigm shift of urban policy in Brazil

\section{Bruno Soeiro Vieira}

Bruno_vieiraa@yahoo.com.br

Professor Titular Pós-Stricto Sensu I da Universidade da Amazônia (UNAMA). Professor no Mestrado em Direitos Fundamentais (UNAMA) Professor no programa de Mestrado e Doutorado em Desenvolvimento e Meio Ambiente Urbano (UNAMA) Pesquisador CNPQ (Grupo de Estudo e Pesquisa em Direito À Cidade). Coordenador da Região Norte do Instituto Brasileiro de Direito Urbanístico (IBDU), no biênio 2018/2019.

Doutor em Direito (Pontifícia Universidade Católica de São Paulo). Doutor em Desenvolvimento Sustentável do Trópico Úmido (NAEA/UFPA).

\section{RESUMO}

A política urbana brasileira avançou após 20 anos do Estatuto da Cidade. Porém, é imprescindível que essa seja aperfeiçoada no sentido de torná-la efetiva em sua plenitude. Portanto, entendemos que o $\$ 1^{\circ}$ do art. 40 do referido diploma devem ser cumpridos pelos municípios, para que as prioridades e diretrizes do plano diretor sejam incorporadas nas leis orçamentárias. Assim, objetivamos identificar a visão predominante entre os urbanistas brasileiros quanto à obrigatoriedade de integração das leis orçamentária-financeiras às diretrizes e prioridades contidas nos planos diretores. Para tanto, desenvolvemos uma pesquisa empírica de natureza exploratória, aplicando questionários a duas classes de atores (servidores públicos de tribunais de contas e urbanistas) como técnica de coleta de dados. Como principais resultados, podemos informar que ainda é diminuto o número de tribunais de contas no Brasil que fiscalizam a aplicação do disposto no $\$ 1^{\circ}$ do artigo 40 do Estatuto da Cidade, assim como, os urbanistas brasileiros defendem que a eficácia da política urbana (instrumentos e políticas setoriais) será algo possível, se o modelo de planejamento municipal integral for uma realidade nas cidades.

Palavras-chave: Planejamento Municipal. Efetividade. Tribunais de Contas. Estatuto da Cidade.

\section{ABSTRACT}

Brazilian urban policy advanced after 20 years of the City Statute. However, it is imperative that that one be perfected in the sense of making it effective in its fullness. Therefore, we understand that $\$ 1^{\circ}$ of Art. 40 of the aforementioned statute must be complied with by the municipalities, so that the priorities and guidelines of the master plan are incorporated in the budget laws. Thus, we aim to identify the predominant view among Brazilian urban planners regarding the mandatory integration of budget-financial laws with the guidelines and priorities contained in the master plans. Therefore, we developed an empirical research of exploratory nature, applying questionnaires to two classes of actors (public servants of the audit courts and urban planners) as a data collection technique. As main results, we can inform that the number of audit courts in Brazil that oversee the application of the provisions of $\$ 1^{\circ}$ of Article 40 of the City Statute is still small, as well as that Brazilian urban planners defend that 
the effectiveness of urban policy (instruments and sectorial policies) will be something possible, if the integral municipal planning model is a reality in the cities.

Keywords: Municipal Planning. Effectiveness. Courts of Auditors. City Statute.

\section{INTRODUÇÃO}

O planejamento é uma ferramenta estatal fundamental ao desenvolvimento (sustentável e sustentado) dos municípios e das regiões metropolitanas no Brasil. Para tanto o legislador constituinte (capítulos: das finanças públicas e da política urbana), bem como, o legislador infraconstitucional (Lei $n^{\circ} 4.320 / 64$ e Lei Complementar no 101/2000, por exemplo) estabeleceram diversas normas jurídicas regulando a matéria planejamento, desde o aspecto orçamentário-financeiro até o tema ligado ao planejamento do desenvolvimento socioespacial municipal (Lei no 10.257/2001).

Em uma interpretação sistemática da ordem jurídica nacional é fácil perceber que o legislador tem muita preocupação com a matéria e deseja fortemente que o planejamento municipal seja resultado de uma construção e aplicação integrada e integral, na qual todos os diplomas legais, cujo escopo seja o planejamento, estejam concatenados visando efetivar um processo racional e global de planejamento das municipalidades.

Sendo assim, esta pesquisa tem como eixo de execução o seguinte problema de pesquisa: Quais os entendimentos dos urbanistas brasileiros sobre o potencial de mudança paradigmática no planejamento urbano municipal se houver a compatibilização das leis orçamentário-financeiras com as diretrizes e prioridades contidas nas leis dos planos diretores?

No intuito de viabilizar a resposta ao problema acima, entendemos que será necessário atingirmos os seguintes objetivos: Geral: identificar a visão preponderante entre os urbanistas brasileiros acerca da obrigatória integração das leis orçamentário-financeiras com as diretrizes e prioridades contidas nas leis dos planos diretores; Específicos: 1) contextualizar a evolução da política urbana no Brasil; 2) demonstrar a importância das leis orçamentário-financeira no âmbito do planejamento municipal; 3) analisar o entendimento dos urbanistas brasileiros acerca da integração entre as leis de planejamento municipal e o potencial impacto na efetividade dos instrumentos urbanísticos e das políticas setoriais municipais.

No que tange à metodologia, desenvolveremos uma pesquisa exploratória visando obter mais informações sobre o funcionamento dos tribunais de contas acerca dos procedimentos de fiscalização a respeito da adequação das diretrizes e dos objetivos dos planos diretores pelas leis orçamentário-financeira, bem como, quais os entendimentos dos urbanistas brasileiros sobre a potencial mudança paradigmática na órbita da política urbana, caso as leis orçamentárias assimilem em seus conteúdos os objetivos e as diretrizes definidas democraticamente pela sociedade e inseridas no instrumento básico da política de desenvolvimento e expansão urbana que é o plano diretor, tal como disposto no Art. 40 do Estatuto da Cidade (BRASIL, 2001).

Sendo assim, esta pesquisa parte da hipótese de que a adoção de um paradigma de planejamento municipal integral gerará um aperfeiçoamento na construção e na execução da política de desenvolvimento municipal que, por consequência, gerará a efetividade dos instrumentos urbanísticos e das políticas setoriais urbanas, devido ao fato das prioridades e diretrizes contidas no plano diretor estarem 
lastreadas por previsão de receita pública suficiente ao custeio (despesa) de todas as ações (prioridades e diretrizes) de política do desenvolvimento municipal.

Como técnica de coleta de dados, decidimos elaborar e enviar dois formulários. O primeiro será direcionado aos servidores públicos que atuam nos tribunais de contas do Brasil e que, portanto, têm lugar de fala quanto ao objeto pesquisado. Por sua vez, o segundo formulário eletrônico terá como destinatários os urbanistas brasileiros. Neste caso, almejamos extrair o entendimento desses profissionais e pesquisadores sobre o previsto no $\$ 1^{\circ}$ do Art. 40 do Estatuto da Cidade (BRASIL, 2001), sobretudo, quanto a força e completude que dispõe um planejamento municipal integral (que harmonize todas as leis de planificação municipal) e as possíveis consequências no modelo de política urbana implementado pelas municipalidades. Destarte, devido a utilização da técnica de coleta descrita, entendemos que estamos diante de uma pesquisa empírica, afinal, trata-se de esforço científico no qual as conclusões serão obtidas estritamente de evidências empíricas, ou seja, concretas e verificáveis.

Assim sendo, o artigo será dividido em seções, sendo que a primeira discorrerá sobre a relevância do Estatuto da Cidade (BRASIL, 2001), principalmente, sua importância na consolidação e institucionalização do planejamento municipal após a sua aprovação.

A segunda seção versará sobre a importância das leis orçamentárias e concepção de um planejamento municipal integral, ou seja, um modelo de integração e harmonização de todas as leis municipais relacionadas ao planejamento das municipalidades, visando, em última análise, a efetividade das políticas setoriais e da aplicação dos instrumentos urbanísticos e, por consequência, gerar o desenvolvimento sustentável e contínuo dos municípios brasileiros.

A última seção consistirá na análise dos dados coletados juntos aos servidores públicos e os urbanistas no intuito de ter elementos suficientes para responder ao problema de pesquisa.

\section{POLÍTICA URBANA, ANTES E DEPOIS DO ESTATUTO DA CIDADE}

Sabemos que a Constituição Federal de 1988 deixou patente que, em matéria urbanística e no âmbito da legislação concorrente, cabe à União editar norma geral. Tal competência legislativa foi exercida com a edição do Estatuto da Cidade (quase 12 anos após o advento da Carta de 1988). Entretanto, antes mesmo do texto constitucional vigente ter sido promulgado em 5 de outubro de 1988, o Movimento Nacional pela Reforma Urbana (MNRU) já estava articulado para defender a adoção de um novo paradigma de planejamento do desenvolvimento urbano, no qual a cidade fosse acessível a todos, a cidadania - na acepção ampla defendida por Santos (2014) - estivesse assegurada e o direito à cidade fosse universalizado àqueles que habitam as manchas urbanas no Brasil. Em outros termos, aquele conjunto de mulheres, homens e entidades almejavam organizar a sociedade civil e criar as bases conceituais necessárias à implementação de uma ampla reforma urbana que fosse capaz de diminuir as desigualdades sociais, econômicas e espaciais tão flagrantes até os dias atuais.

Ilustrando o acima mencionado, segue a transcrição:

O Movimento Nacional pela Reforma Urbana articulou o cenário de participação popular em todo o Brasil no processo da Constituinte de 1988, formado por um grupo heterogêneo, cujos participantes atuavam em diferentes e complementares temáticas do campo urbano. Reuniu-se 
uma série de organizações da sociedade civil, movimentos, entidades de profissionais, organizações não-governamentais, sindicatos. (SAULE; UZZO, [s.d.])

As sementes daquela ampla articulação promovida pelo MNRU germinaram com a inclusão de um capítulo específico destinado à política urbana no corpo da Carta da República (algo inédito na história constitucional brasileira), bem como, na edição da lei brasileira de desenvolvimento urbano, conhecida por todos como Estatuto da Cidade (BRASIL, 2001).

Devemos registrar que em 2001, de acordo com os dados do Instituto Brasileiro de Geografia e Estatística (IBGE, 2001), a população brasileira estava em torno de 172 milhões de habitantes, em sua maioria vivendo nos perímetros urbanos. Logo, naquele momento o Brasil já era um país eminentemente urbano, cujas cidades se caracterizavam pela segregação socioespacial e a negação ao direito à cidade.

De acordo com o IBGE (BRASIL, 2015), a população urbana era de 84,72\% e em 2020, eram 49 (quarenta e nove) os municípios brasileiros com mais de 500 mil habitantes e, destes, 17 (dezessete) superavam a marca de 1 milhão de habitantes (BRASIL, 2020). Portanto, atualmente, o Brasil tem dezessete municípios "milionários" (em número de habitantes), mas também, ricos em pobreza e desigualdade.

\subsection{Duas décadas depois}

Foram muitos e consideráveis os avanços na questão urbana promovidos após a vigência do Estatuto da Cidade (BRASIL, 2001), tais como: a formulação de políticas urbanas pautadas na participação social (fortalecimento do planejamento e da gestão democrática) e o aumento expressivo na aprovação do plano diretor por parte dos municípios brasileiros, pois, segundo a pesquisa MUNIC do IBGE (BRASIL, 2019), o percentual de municípios brasileiros com o mencionado plano era próximo a 50\% e aqueles com mais de 20.000 (vinte mil) habitantes (obrigados à edição do plano diretor) chegava 90,1\%. Logo, fica evidente que houve uma positiva evolução na consolidação de uma lógica institucional de construção da política urbana se comparada com o cenário anterior ao Estatuto da Cidade (BRASIL, 2001).

No entanto, o poeta popular já dizia que nem tudo são flores e, neste caso, após a consolidação da ordem urbana normativa no país, resta ainda garantir que ela seja efetivada, afinal, não se pode admitir a existência de milhares de normas urbanísticas municipais, sem que elas produzam efeitos concretos no universo urbano e metropolitano e, portanto, não sejam capazes de auxiliar na construção de cidades nas quais o direito à cidade seja uma realidade.

Infelizmente, após uma expressiva evolução no campo da política urbana, estamos diante de uma encruzilhada, tendo que admitir a existência de dois caminhos. O primeiro seria a continuidade do quadro atual, ou seja, a inefetividade flagrante da política urbana, quando as políticas setoriais e os instrumentos previstos no Estatuto da Cidade, nos planos diretores e demais leis urbanísticas não são aplicados ou, ainda, são utilizados de modo mitigado, a partir de estratégias políticas de determinados agentes que produzem o espaço urbano, sobretudo, os agentes do capital imobiliário que obstaculizam grandemente a implementação do arsenal de instrumentos previstos no Estatuto da Cidade (BRASIL, 2001).

Nesse caminho indesejado e impróprio ao desenvolvimento sustentável das cidades, podemos observar a existência de um teatro da política urbana onde é encenada uma obra de ficção na qual a cidade tem regras e princípios de planejamento municipal que regulam o uso e a ocupação do solo e do espaço 
urbano de modo sustentável, equitativo e democrático, de modo que as funções sociais da cidade sejam a todos garantidas. Entretanto, como toda obra ficcional, essa encenação evidencia um descolamento da realidade urbana, neste caso, as cidades que dispõem de um conjunto de normas de cunho urbanístico não implementam, plena e concretamente, as políticas setoriais e os instrumentos urbanísticos contidos no citado conjunto normativo, implicando em uma expressiva inefetividade daquelas ferramentas que podem reconfigurar o espaço urbano de modo a torná-lo acessível, sustentável, equitativo e democrático.

Para ilustrar quando utilizamos o termo "ficção", transcrevemos o entendimento seguinte:

\footnotetext{
Uma intensa campanha publicitária leva uma ficção à população: o que se faz em território restrito e limitado ganha foros de universal. Os investimentos na periferia não contam para a dinâmica do poder político, como os próprios excluídos não constam para o mercado. E o que é mais trágico, a priorização das políticas sociais frequentemente não conta para os próprios excluídos cujas referências são a centralidade hegemônica. (MARICATO, 2013).
}

A outra via seria aquela na qual a ordem urbana é resultado de um arranjo democrático e plural, na qual os instrumentos urbanísticos e as políticas setoriais são verdadeiramente construídas, aplicadas e geridas pela sociedade em toda a sua diversidade, transformando as urbes de espaços informais de segregação socioespacial em cidades justas, sustentáveis, plurais e acessíveis a todos, independentemente da renda, da cor ou do credo de seus habitantes.

Nossa impressão é que a maior parte dos municípios brasileiros que dispõem de planos diretores e outras leis de natureza urbanística, visam tão somente cumprir superficialmente os comandos expressos no texto constitucional e no Estatuto da Cidade e, desse modo, evitar que os gestores sofram as sanções previstas no ordenamento jurídico nacional. Portanto, são leis para “inglês ver", são leis de "perfumaria", ou seja, ficções normativas que em nada ou quase nada contribuem com o planejamento do desenvolvimento dos municípios, mas que servem para eximir os prefeitos de punições ou de crime de improbidade, tal como determina o Art. 52 do Estatuto da Cidade (BRASIL, 2001).

Sobre as leis de "perfumaria", decidimos ilustrar com a transcrição da lição de Maricato (2013): "não é por falta de planos e nem de legislação urbanística que as cidades brasileiras crescem de modo predatório. Um abundante aparato regulatório normatiza a produção do espaço urbano [...] demonstrando que a exclusão social passa pela lógica da aplicação discriminatória da lei”. Destarte, é necessário que saiamos do plano ficcional, no qual as leis de "perfumaria" imperam, para que tenhamos uma ordem urbana capaz de contribuir com a configuração e reconfiguração de cidades sustentáveis, plurais e equitativas.

\section{O PLANEJAMENTO MUNICIPAL INTEGRAL}

No tocante à evolução do orçamento ou, de modo mais amplo, das leis orçamentárias, fazemos o registro que de acordo com a lição Oliveira (2008), o "orçamento, tal como existe no mundo de hoje, não era conhecido na antiguidade". Em Roma, por exemplo, havia uma confusão entre o orçamento Estatal com aquele relativo à riqueza pessoal do imperador, situação que começou a mudar quando, no de 1215, os barões conseguiram aprovar a Magna Carta à João Sem Terra, criando um ponto de inflexão na história dos orçamentos, isto porque, a partir daquele momento, os tributos só poderiam ser exigidos, após a concordância de um conselho (OLIVEIRA, 2008). 
Ao caminharmos na história, chegamos à época do liberalismo e notamos que na mesa trilha está o entendimento de Bastos (2002) sobre a evolução da importância do orçamento e seu objetivo precípuo, como segue:

Sua inspiração última é de se tornar um instrumento de exercício da democracia pelo qual os particulares exercem o direito, por intermédio de seus mandatários, de só verem efetivadas as despesas e permitidas as arrecadações tributárias que estiverem autorizadas na lei orçamentária. (BASTOS, 2002)

Extraímos da transcrição acima que o orçamento (no caso brasileiro: são leis de natureza orçamentária), é um instrumento da democracia que serve de contenção à eventuais exigências arbitrárias de tributos, bem como, de desembolso de recurso que não vise o interesse da coletividade.

Logo, se as leis de planejamento orçamentário-financeiro são ferramentas ao exercício da democracia, nada mais lógico entendermos que o conteúdo destas deve materializar os valores e interesses da maioria da sociedade, em especial neste artigo, as demandas relativas à política urbana, por meio de uma receita pública necessária à consecução de obras e serviços (despesas) de intervenção na cidade (políticas setoriais): de habitação, de saneamento, de mobilidade, de uso e ocupação do solo e do espaço urbano, de proteção e recuperação do patrimônio histórico edificado, etc...

Não podemos olvidar que a construção dos diplomas legais de natureza orçamentária-financeira deve (em seu sentido mais forte) ter origem nas arenas e foros de discussão participativa, quando desde o início da elaboração, até a consequente aprovação pelo parlamento municipal, das minutas do plano plurianual (PPA), das diretrizes orçamentárias (LDO), do orçamento anual (LOA) e da lei do plano diretor (PD), a sociedade esteja autorizada a contribuir e opinar sobre quais as diretrizes e objetivos a planificação estatal deve priorizar.

Sendo assim, transcrevemos o trecho seguinte visando ratificar o nosso entendimento, textuais:

Portanto, o orçamento público é um documento que tende a contribuir para a avaliação da execução de políticas públicas e o atingimento dos resultados esperados (metas, diretrizes, etc). A participação ocorre não apenas por meio da representação da cidadania via poder legislativo, mas do cidadão, por meio de conselhos, organizações associativas, audiências públicas e outras formas de engajamento no desenho e na exigência das demandas planejadas para o orçamento. $\mathrm{Ou}$ seja, a participação cidadã é essencial no processo orçamentário, na perspectiva da accountability democrática ${ }^{1}$, o que é potencializado pelo conhecimento do cidadão de meios para acompanhar a execução orçamentária e implementação de uma política pública. (MELO, 2020)

Desse modo, tal como em uma dança na qual os casais de dançarinos precisam estar no mesmo compasso e ritmo, as leis de planejamento municipal precisam estar na mesma toada, ou seja, necessitam estar harmonizadas formando um processo normativo integrado e compatível com a Constituição Federal (BRASIL, 1988), com o Estatuto da Cidade (BRASIL, 2001) e com o Estatuto da Metrópole (BRASIL, 2015).

O Estatuto da Cidade (BRASIL, 2001) deixa bem evidente que as leis que compõem o planejamento municipal são: o plano diretor, o PPA, a LDO e a LOA. Contudo, o plano diretor ganhou ênfase no texto do Estatuto da Cidade ao dispor que as demais leis municipais de planejamento devem incorporar as diretrizes e as prioridades contidas na lei do plano diretor: $\$ 1^{\circ}$ do Art. $40^{2}$ (BRASIL, 2001).

\footnotetext{
1 Nossa perspectiva sobre o conceito de accountability democrática diz respeito controle multidimensional das políticas púbicas, no qual diversos atores e agentes que produzem o espaço urbano atuam ao lado e, sob a motivação do administrador público que fomenta a participação e o controle social de todas as políticas públicas.

2 Regra fundante do planejamento municipal integral
} 
Faz todo o sentido a lógica normativa acima mencionada, pois ao incluir o plano diretor no contexto das leis de planejamento municipal, permite que o instrumento básico da política de desenvolvimento e expansão urbana (plano diretor) esteja conectado e compatível com toda a perspectiva de planificação do futuro do município, afinal, não bastam apenas as boas intenções por parte dos gestores e técnicos municipais se não existir um planejamento de captação (receita) e de desembolso (despesa) dos recursos financeiros por parte das municipalidades que estejam em estreita harmonia com as diretrizes e as prioridades enunciadas no plano diretor municipal.

Em interessante dissertação sobre o objeto desta pesquisa, Melo (2020) informa que o PD estabelece o plano de ação como instrumento de gestão para a realização das diretrizes definidas nas diversas políticas públicas municipais, compatibilizando-as com as leis orçamentárias, visando, em última análise, prever os recursos necessários ao cumprimento dos instrumentos de planejamento.

Sendo assim, na dança da configuração e reconfiguração do espaço urbano, as leis que compõem o processo de planejamento municipal devem estar no mesmo ritmo e compasso, ou seja, devem ser concebidas por meio de um processo integrado de modo que as diretrizes, objetivos e metas da administração pública contidas no PPA (planejamento de longo prazo) estejam em conformidade com as metas e prioridades contidas na LDO, bem como, com as regras existentes na lei de execução orçamentária (LOA) e, por sua vez, todas em consonância com as diretrizes e prioridades de natureza urbanística dispostas na lei do plano diretor, tais como: saneamento urbano, mobilidade urbana, preservação e recuperação do patrimônio cultural, habitação, regularização fundiária, desapropriações etc...

Desse modo, não bastando a cogência contida no previsto no $\$ 1^{\circ}$ do Art. 40 do Estatuto da Cidade (BRASIL, 2001), decidimos reforçar a fundamentação que justifica a adoção obrigatória de um paradigma de planejamento municipal integral, interligando as leis orçamentárias às diretrizes e objetivos contidos no plano diretor.

O reforço faz-se necessário porque o modelo de federalismo fiscal existente no Brasil que, apesar de propor a inexistência de hierarquia e a autonomia entre os entes que compõem a federação, em verdade, tem gerado forte assimetria entre as entidades da federação, mormente, em relação à autonomia financeira dos entes subnacionais (municípios), pois devido a citada assimetria na repartição da receita tributária entre os entes, os municípios findam por serem os entes com o maior descompasso entre suas atribuições constitucionais e legais (saúde, educação, etc...) e os recursos financeiros a disposição para o custeio das diversas políticas públicas sob sua responsabilidade.

A respeito da ausência de hierarquia entre os entes da federação e as atribuições de cada entidade, segue o fragmento, in verbis:

Laboram em erro os que vêem uma relação hierárquica entre o governo central e os governos locais. O que há, na verdade, são, para cada uma dessas entidades políticas, campos de atuação autônomos e exclusivos, estritamente traçados na Carta Suprema, que lei alguma pode alterar. (CARRAZA, 1997)

Sendo assim, em tese, não existe uma preponderância de um ente sobre outro. No entanto, ao analisarmos o rateio do poder tributário, ou seja, a repartição das receitas tributárias entre as entidades da federação, de acordo com o previsto na Carta da República, fácil compreender que há um hiato entre o que a teoria defende e aquilo que realidade impõe. Infelizmente, o resultado da análise acima 
mencionada obriga-nos a perceber o grande desequilíbrio entre entes federados, do qual chama atenção a grande dependência financeira dos entes subnacionais (municípios) ao poder central.

Na mesma toada é a lição transcrita, textuais:

Ressalte-se que a discriminação de rendas com tributos é um dos indicadores do modelo federalista proposto a um Estado, e também método de constatação dos graus de autonomia dos entes que o formam. Nesses termos, pode ser considerada “elemento nuclear do federalismo". (ELALI, 2005).

Logo, se não há autonomia financeira de determinado ente, será este obrigado a pedir auxílio a outra entidade da federação. Destarte, apesar de sabermos que não existe um standard quando se fala em estrutura federativa, estamos muito aquém da Alemanha, por exemplo, no quesito autonomia financeira, porque em superficial análise comparativa, percebemos que naquele país há um equilíbrio entre conjunto de atribuições que o ente subnacional possui e sua receita tributária, dando ensejo à presença do princípio da subsidiariedade ${ }^{3}$, situação bem distinta da que observamos no Brasil.

Este desequilíbrio entre o volume de atribuições e o da receita pública, demonstra a fragilidade do atual modelo de federação, pois este modelo de Estado foi concebido para gerar a descentralização. Todavia, a citada assimetria que vem se agravando ao longo das últimas décadas tem feito com que os municípios se tornem cada vez mais dependentes dos demais entes federados, sobretudo, do governo federal.

Portanto, se há problema na gestão orçamentária-financeira pelos municípios, fruto deste assimétrico arranjo federativo, nada mais lógico entender que o planejamento do desenvolvimento urbano esteja inserido dentro do processo integral de planejamento das municipalidades, quando o PPA, a LDO e a LOA "devem" incorporar as diretrizes e as prioridades contidas no plano diretor, este que, segundo o próprio Estatuto da Cidade (BRASIL, 2001), "é o instrumento básico da política de desenvolvimento e expansão urbana”. Destarte, talvez com esta alteração de postura na planificação municipal seja possível constatarmos uma efetiva execução da política urbana que contribuirá com a garantia do direito à cidade à todos.

Desse modo, desde que começamos a estudar e, posteriormente, pesquisar sobre a questão urbana e metropolitana, o plexo normativo que à sustenta e sua necessária interdisciplinaridade, sempre tivemos a curiosidade em saber se o previsto $\$ 1^{\circ}$ do Art. 40 do Estatuto da Cidade (BRASIL, 2001) seria ou não respeitado, afinal, tal como acima dito, naquele momento estava em curso o processo de consolidação institucional na maioria dos municípios brasileiros. Portanto, era momento de lutar para que fosse maior o número de municípios com plano diretor.

Contudo, entendemos que há algum tempo a ordem urbana já iniciou um novo estágio de aprimoramento, momento no qual as municipalidades precisam utilizar efetivamente todas as possibilidades contidas no plano diretor e nas demais leis urbanísticas, seja por meio da execução de políticas setoriais ou, ainda, através da aplicação integral dos diversos instrumentos urbanísticos, no intuito de transformar os municípios para que o desiderato previsto no caput do Art. 182 da Constituição Federal (BRASIL, 1988) seja alcançado e possamos testemunhar a existência e o gozo das funções sociais da cidade por todos os seus habitantes.

Assim, após este modesto diagnóstico conjuntural, indago-mo-nos: de que maneira as municipalidades poderão avançar no campo da política urbana, de modo que as normas de planejamento

3 O princípio da subsidiariedade ordena as competências estatais, preconizando que as decisões devem ser tomadas prioritariamente pela entidade mais eficiente, neste caso, os municípios (segundo o arranjo institucional do federalismo brasileiro). As exceções seriam as situações nas quais os municípios não detenham capacidade para resolver a demanda, situação que exigirá que as demais entidades da federação auxiliem o ente sem capacidade de resolução. 
municipal sejam construídas harmonicamente e, mais importante, sejam úteis ao planejamento do desenvolvimento urbano? Como as normas de natureza urbanística deixarão de ser apenas o invólucro e sejam o conteúdo da política urbana?

Os questionamentos que fazemos dizem respeito à profunda preocupação com a inefetividade dessa já consolidada ordem urbana, isto porque este conjunto de normas de direito não tem gerado a repercussão necessária à transformação urgente das cidades brasileiras e, como consequência, as urbes continuam a ser a fotografia mais verdadeira e cruel da injustiça social, da segregação espacial e da negação do direito à cidade.

Desse modo, compreendemos que o ministério público, a defensoria pública e a sociedade civil são aqueles agentes que têm a força e influência suficientes para alterar a rota da política urbana no Brasil.

É fundamental que lembremos do potencial papel institucional do ministério público que tem o dever de defender a ordem jurídica, o regime democrático, bem como, os interesses sociais e individuais indisponíveis, devendo empenhar-se para que a ordem urbana seja cumprida integralmente.

$\mathrm{Na}$ mesma trilha, não podemos olvidar da missão institucional da defensoria pública que deve atuar na promoção dos direitos humanos e como o meio ambiente urbano é um direito humano, também deve a defensoria se empenhar para que a ordem urbana seja aplicada plenamente.

Outro agente importante é a sociedade civil que, armada das regras e princípios jurídicos que evidenciam que a política urbana precisa ser concebida, executada e gerida por meio de um processo de gestão democrática, deverá contribuir neste novo caminho que entendemos ser o mais apropriado à construção de cidades plurais, sustentáveis e justas.

Sem dúvida, todos os agentes citados têm sua importância e devem atuar em conjunto na construção e efetivação da ordem urbana, objetivando garantir que a política de desenvolvimento urbano seja capaz de disciplinar o desenvolvimento das funções sociais da cidade e, em última análise, garantir que todas as mulheres e homens que habitam nas cidades vivam com dignidade, tal como almejou o legislador constituinte ao redigir o Art. 182 da Constituição Federal (BRASIL, 1988).

Entretanto, sabemos que a cidade é uma arena de lutas na qual os agentes que produzem o espaço urbano, por muitas vezes, têm valores e interesses antagônicos, por exemplo: 1) relativos à área que representa a história e a cultura de uma cidade; 2) relacionados ao uso e a ocupação dos leitos de rios e praias; e 3) sobre o coeficiente de aproveitamento. Neste cenário, evidencia-se ainda mais necessário e urgente que as leis de planejamento municipal, o PPA, a LDO, a LOA estejam interligadas e incorporem as diretrizes e as prioridades contidas na lei do plano diretor.

Assim, em um ambiente conflituoso é fundamental que as leis de planejamento estejam soando a mesma melodia, estejam harmonizadas permitindo que as prioridades, assim como, as diretrizes dispostas no plano diretor sejam inseridas e estejam respaldadas nas regras típicas do planejamento orçamentário-financeiro. Caso contrário, não serão suficientes as boas intenções em realizar um planejamento do desenvolvimento útil a todos, se não houver uma previsão de receita (recursos financeiros) que seja suficiente para garantir que certa intervenção urbana aconteça. Em outros termos, as prioridades e as diretrizes contidas no plano diretor devem estar acompanhadas de uma estimativa de receita suficiente para sustentar o desembolso necessário (despesa) à realização de ações de intervenção urbana.

Para que tal lógica de planejamento municipal seja implementada é fundamental que existam ações rotineiras de fiscalização por parte dos órgãos de controle externo, sobretudo, os tribunais de 
contas e o ministério público junto aos tribunais de contas. Afinal, existe uma determinação normativa expressa no $\$ 1^{\circ}$ do Art. 40 do Estatuto da Cidade (BRASIL, 2001) que determina que as leis orçamentárias incorporem as diretrizes e as prioridades contidas no plano diretor. Logo, se tal dispositivo está em vigor, não foi considerado inconstitucional, deve ser cumprido e os tribunais de contas têm o poder-dever de fiscalizar o seu cumprimento.

Enfim, dessa maneira teremos a chance de ter um processo de planejamento do desenvolvimento urbano que esteja em consonância com o paradigma expresso no Estatuto da Cidade (BRASIL, 2001), no qual as boas intenções dos gestores públicos e dos agentes que produzem o espaço urbano estejam respaldadas em normas jurídicas que garantam verdadeiramente que as diretrizes e as prioridades (boas intenções) escolhidas democraticamente pela sociedade serão executadas. Caso contrário, continuaremos a ser meros espectadores da obra de ficção que tem sido a política urbana no Brasil.

\section{A MUDANÇA PARADIGMÁTICA DA POLÍTICA URBANA NA VISÃO DOS URBANISTAS BRASILEIROS}

Visando responder ao problema de pesquisa, resolvemos coletar dados preliminares por meio de dois formulários eletrônicos, deixando claro, desde já, que se trata de uma pesquisa exploratória que requererá maior aprofundamento, mas que deixará uma trilha de dados e informações úteis a todos e todas que desejarem entender a (in) efetividade do $\$ 1^{\circ}$ do Art. 40 do Estatuto da Cidade (BRASIL, 2001) e as repercussões advindas do (des) respeito à tão importante norma jurídica que, em nosso entendimento, torna cogente o paradigma de planejamento municipal integral.

$\mathrm{Na}$ tabela abaixo evidenciaremos o conteúdo dos dois formulários, as perguntas formuladas, bem como, a quais e quantos atores foi direcionado cada um dos formulários e, por consequência, o número de respostas.

Tabela 1: Conteúdos dos formulários eletrônicos

\begin{tabular}{|c|c|c|c|c|}
\hline & Questionamentos & $\begin{array}{c}\text { Atores } \\
\text { entrevistados }\end{array}$ & $\begin{array}{c}\mathrm{N}^{0} \text { de questionários } \\
\text { enviados }\end{array}$ & $\begin{array}{c}\mathrm{N}^{0} \text { de } \\
\text { respostas }\end{array}$ \\
\hline 1 & $\begin{array}{l}1.1 \text { Qual dos tribunais de contas você atua? } \\
1.2 \text { A fiscalização do tribunal de contas em que você trabalha verifica se as } \\
\text { leis de planejamento orçamentário-financeiro (PPA, LDO e a LOA) obede- } \\
\text { cem e são compativeis com as diretrizes e prioridades contidas no plano di- } \\
\text { retor Municipal, conforme determina o } \S 1^{\circ} \text { do Art. } 40 \text { do Estatuto da Cidade? }\end{array}$ & $\begin{array}{l}\text { Servidores } \\
\text { públicos que } \\
\text { atuam nos tri- } \\
\text { bunais de con- } \\
\text { tas do Brasil }\end{array}$ & $\begin{array}{l}\text { Enviado para dois } \\
\text { grupos do Whatsapp } \\
\text { que reúnem em torno } \\
\text { de } 90 \text { servidores pú- } \\
\text { blicos. }\end{array}$ & 15 \\
\hline 2 & $\begin{array}{l}\text { 2.1 Ao longo de sua trajetória profissional, V.Sa. teve conhecimento de al- } \\
\text { gum município que respeite o disposto no } \S 1^{\circ} \text { do Art. } 40 \text { do Estatuto da } \\
\text { Cidade: "§ } 1^{0} \text { O plano diretor é parte integrante do processo de planeja- } \\
\text { mento municipal, devendo o plano plurianual, as diretrizes orçamentárias e } \\
\text { o orçamento anual incorporar as diretrizes e as prioridades nele contidas"? } \\
2.2 \text { Se a resposta acima for positiva, qual ou quais seriam esses municí- } \\
\text { pios? Caso contrário, desconsidere esta pergunta. } \\
2.3 \text { Segundo a vossa experiência profissional, está na rotina dos órgãos } \\
\text { de controle externo, em especial, os tribunais de contas, exercer como } \\
\text { rotina a fiscalização da compatibilidade e integração das leis orçamentá- } \\
\text { rio-financeiras com as diretrizes e prioridades contidas no plano diretor? } \\
2.4 \text { Em vossa opinião, se as municipalidades adotarem um paradigma de } \\
\text { planejamento municipal que integre plenamente todas as leis orçamen- } \\
\text { tário-financeiras (PPA, LDO e a LOA) às diretrizes e prioridades contidas } \\
\text { no plano diretor municipal, implicará no aperfeiçoamento e na efetividade } \\
\text { da política urbana? }\end{array}$ & $\begin{array}{l}\text { Urban is ta s } \\
\text { brasileiros de } \\
\text { diferentes for- } \\
\text { mações acadê- } \\
\text { mica. }\end{array}$ & $\begin{array}{l}82 \text { formulários envia- } \\
\text { dos pelo Whatsapp }\end{array}$ & 37 \\
\hline
\end{tabular}

Fonte: Elaborado pelo autor 
O primeiro questionário eletrônico foi submetido a dois grupos de servidores públicos que atuam em tribunais de contas brasileiros, objetivando saber quais cortes de contas públicas no Brasil já adotam sistematicamente a fiscalização da compatibilidade de todas as leis de planejamento municipal (PPA, LDO, LOA e plano diretor).

Após o envio do formulário, obtivemos 15 (quinze) respostas, sendo que destas, apenas 6 (seis) admitem que os tribunais realizam ações de fiscalização voltadas a verificação do atendimento ao previsto no $\$ 1^{\circ}$ do Art. 40 do Estatuto da Cidade (BRASIL, 2001), por parte das municipalidades, ou seja, $40 \%$ dos tribunais já incluíram na sua rotina de fiscalização a análise da compatibilidade entre todas as leis de planejamento municipal.

Gráfico 1: Quantidade de questionários aplicados e de respostas

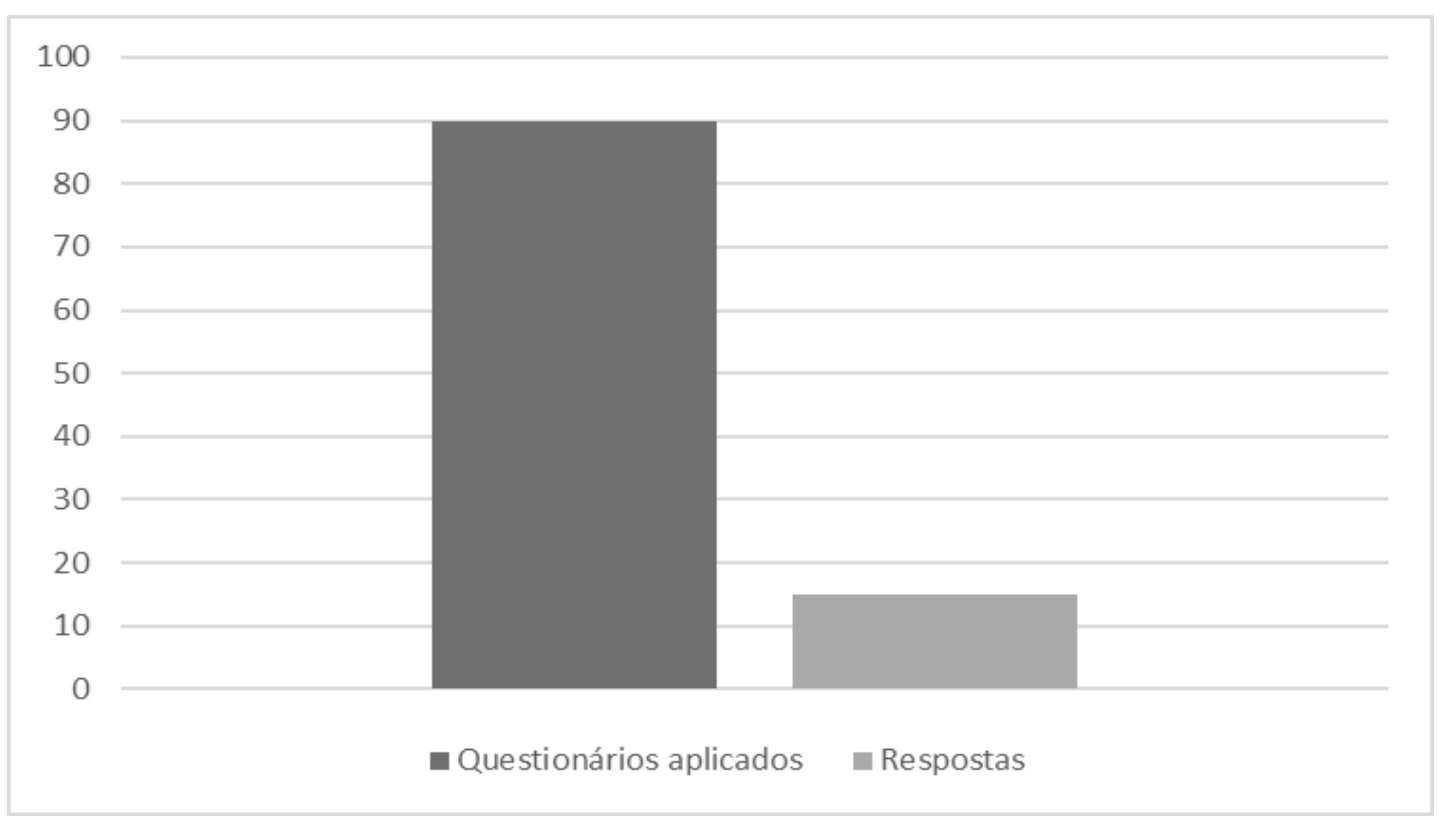

Fonte: Elaborado pelo autor

O número de respostas equivale a $16,67 \%$ dos entrevistados. Trata-se de um percentual pequeno de informações obtidas junto aos servidores públicos, sendo que aqueles que responderam os questionários atuam nos seguintes tribunais de contas: 1) Tribunal de Contas do Município (TCM/SP); 2) Tribunal de Contas do Município (TCM/RJ); 3) Tribunal de Contas do Estado (TCE/RS); Tribunal de Contas do Estado (TCE/SC); Tribunal de Contas do Estado (TCE/MG); Tribunal de Contas do Município (TCM/BA); Tribunal de Contas do Estado (TCE/CE) e Tribunal de Contas dos Municípios (TCM/PA). Todavia, apesar do quantitativo diminuto de respostas obtidas, como estamos diante de uma pesquisa exploratória, entendemos que é viável analisar os dados contidos nos formulários. 
O gráfico seguinte é importante à análise da pesquisa, segue:

Gráfico 2: Percentual de tribunais de contas que fiscalizam ( $\$ 1^{\circ}$ do Art. 40 do EC)

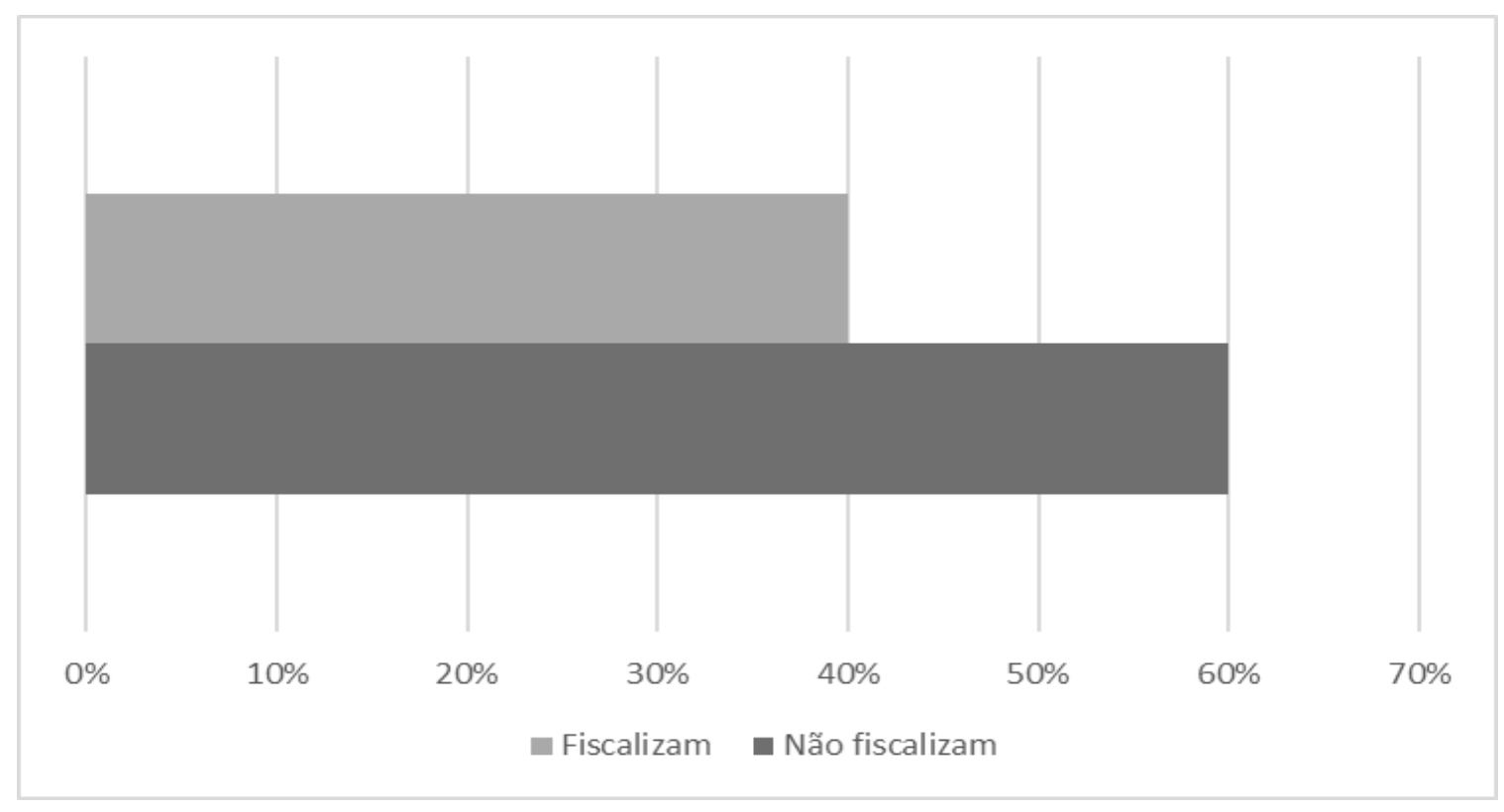

Fonte: Elaborado pelo autor

Assim, conforme o gráfico acima, dentre as respostas acolhidas, podemos observar que $40 \%$ dos tribunais de contas do país adotam procedimento de fiscalização em relação ao disposto no $\$ 1^{\circ}$ do Art. 40 do Estatuto da Cidade (BRASIL, 2001), ao mesmo tempo que gera uma surpresa agradável (afinal, trata-se de um percentual bem expressivo de tribunais que já exercem a fiscalização), por outro lado, é necessário entendermos que ainda é um número insuficiente, isto porque é crucial à governança das contas públicas que todos os órgãos de controle externo (tribunais de contas, Controladoria Geral da União, ministério público junto aos tribunais de contas, Poder Legislativo municipal), bem como, os órgãos de controle interno da administração pública e a sociedade civil (controle social ${ }^{4}$ ), exerçam, na medida de suas competências, ações necessárias à efetivação da lógica de planejamento municipal integral proposta pelo legislador ao redigir o Estatuto da Cidade (BRASIL, 2001).

No que tange ao segundo questionário eletrônico, buscamos extrair informações dos urbanistas brasileiros pelo fato de serem profissionais que atuam, seja no cotidiano da elaboração e/ou implementação de planos urbanísticos, seja na atividade da docência e da pesquisa acadêmica cujo objeto central das destas seja a política urbana e toda a sua ordem normativa. São profissionais com lugar de fala, expertise, portanto, são atores capazes de auxiliar na análise dos dados e, por conseguinte, na resposta do problema de pesquisa.

\footnotetext{
4 Controle Social concebido por nós como o ato dos cidadãos participarem (individual ou coletivamente) nos órgãos colegiados de gestão, bem como, fiscalizando os atos dos órgãos administrativos, com base na legislação, para a defesa do patrimônio público e dos direitos fundamentais previstos na Carta da República. Controle que conta com diversos "dispositivos legais, implantados quando do processo de redemocratização do país durante a década de 1980-90, não só na Constituição Federal de 1988, mas também, pela Lei Complementar n 101, de 04 de maio de 2000 (Lei de Responsabilidade Fiscal - LRF), e nas Leis de Diretrizes Orçamentárias - LDO” (CONCEIÇÃO, 2010).
} 
Gráfico 3: Quantidade de questionários aplicados e de respostas

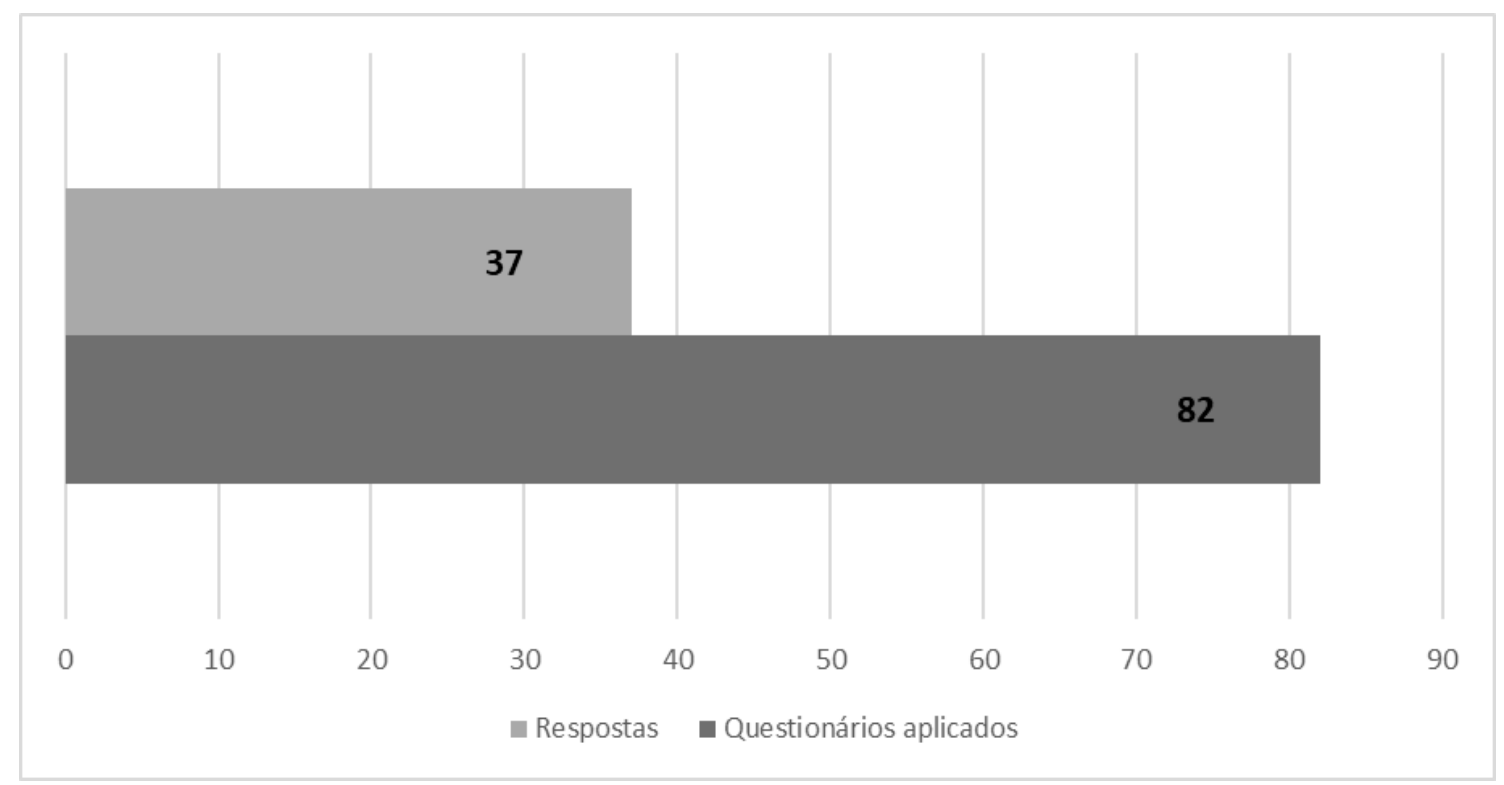

Fonte: Elaborado pelo autor

Desse modo, obtivemos um número bem mais considerável de respostas com a aplicação do segundo questionário, porque das 82 (oitenta e duas) submissões, 37 (trinta e sete) foram respondidas, perfazendo um percentual de $45,12 \%$ de respostas, permitindo-nos atribuir maior certeza aos dados colhidos com a aplicação do segundo questionário.

Dessa maneira, inicialmente indagamos: "Ao longo de sua trajetória profissional, V.Sa. teve conhecimento de algum município que respeite o disposto no $\$ 1^{\circ}$ do Art. 40 do Estatuto da Cidade: $\$ 1^{\circ} \mathrm{O}$ plano diretor é parte integrante do processo de planejamento municipal, devendo o plano plurianual, as diretrizes orçamentárias e o orçamento anual incorporar as diretrizes e as prioridades nele contidas"?

Gráfico 4: Respeito ao planejamento municipal integral ( $\$ 1^{\circ}$ do Art. 40 do EC)

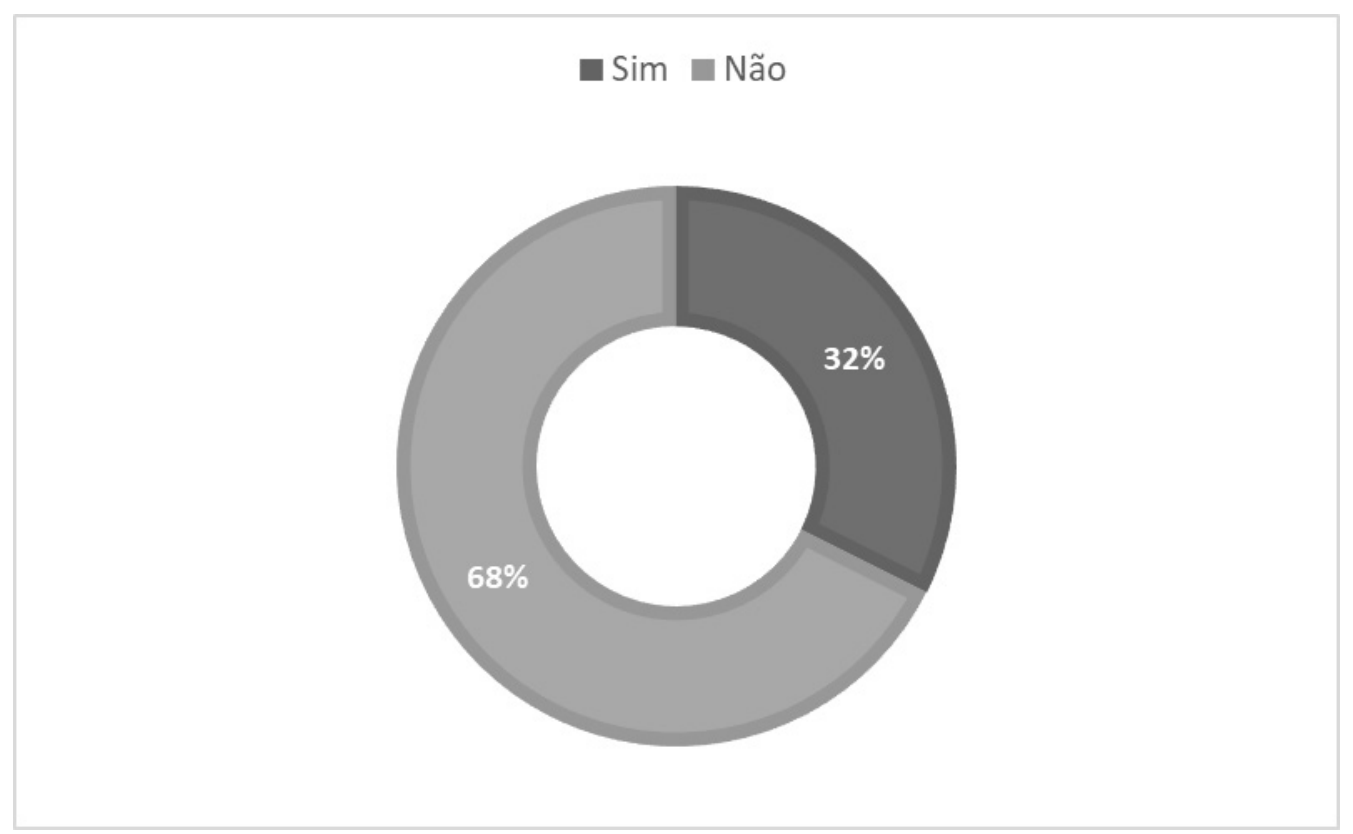

Fonte: Elaborado pelo autor 
Observe que o gráfico acima dá ênfase à postura das municipalidades, ou seja, indagou-se se os urbanistas conhecem concretamente municípios que respeitam o modelo de planejamento integral, compatibilizando as leis de planejamento às diretrizes e prioridades contidas no plano diretor. Portanto, $32 \%$ dos urbanistas admitem que conhecem realidades municipais na qual o $\$ 1^{\circ}$ do Art. 40 do Estatuto da Cidade (BRASIL, 2001) está sendo respeitado.

Outros dados importantes foram colhidos com a aplicação da seguinte pergunta: "Segundo a vossa experiência profissional, está na rotina dos órgãos de controle externo, em especial, os tribunais de contas, exercer como rotina a fiscalização da compatibilidade e integração das leis orçamentário-financeiras com as diretrizes e prioridades contidas no plano diretor?" O gráfico seguinte evidencia as respostas.

Gráfico 5: Fiscalização dos tribunais de contas na ótica dos urbanistas

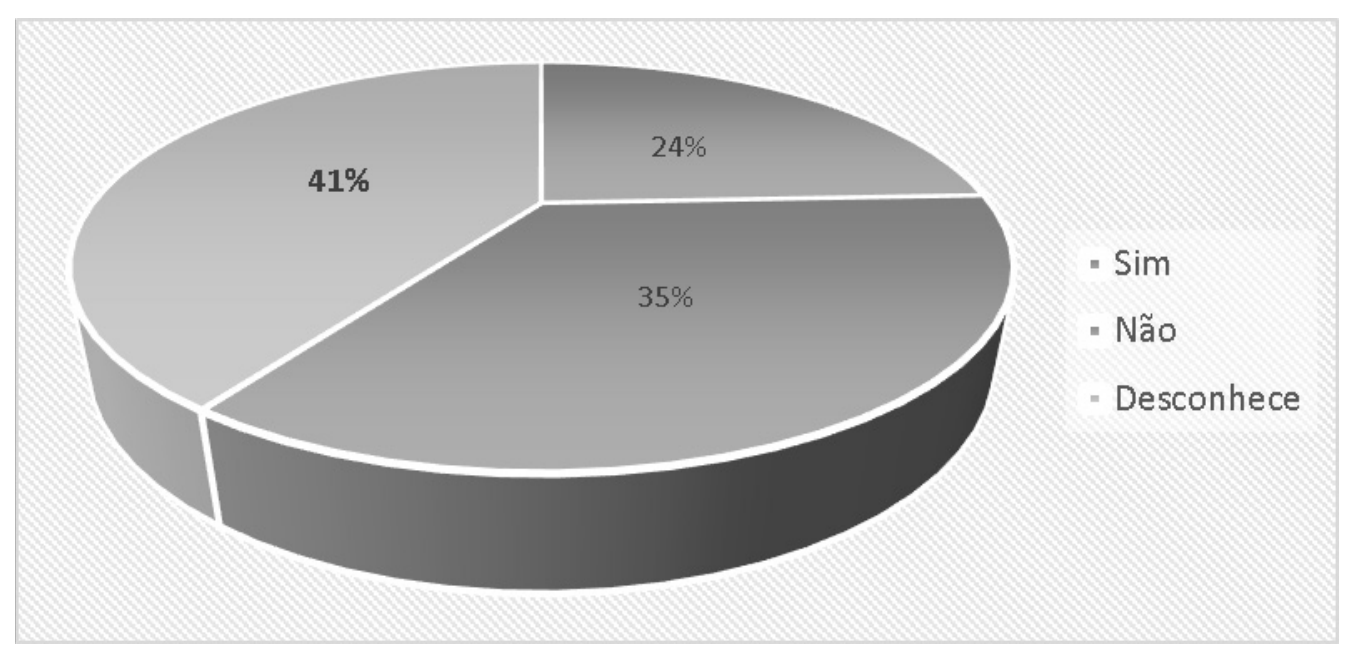

Fonte: Elaborado pelo autor

Ao analisar o gráfico 5 e confrontá-lo com os dados do gráfico 2, evidencia-se uma divergência importante, pois de acordo com as respostas dos servidores públicos, $40 \%$ dos tribunais de contas adotam procedimento de fiscalização que visam aferir se a regra fundante do planejamento municipal integral está sendo obedecida, ao passo que, segundo os urbanistas, apenas $24 \%$ dos tribunais de contas exercem a fiscalização sobre a compatibilidade das normas de planejamento municipal (PPA, LDO, LOA e Plano Diretor).

Talvez a divergência expressiva seja fruto do diminuto quantitativo de respostas do primeiro questionário, aquele aplicado exclusivamente aos servidores públicos, quando apenas $16,67 \%$ dos entrevistados atenderam o convite para contribuir com esta pesquisa.

Chamou atenção o fato que $41 \%$ dos urbanistas desconhecerem sobre a rotina de fiscalização dos órgãos dos tribunais de contas em relação a fiscalização da compatibilidade e integração das leis orçamentário-financeiras com as diretrizes e prioridades contidas no plano diretor. Tal dado gerou outra pergunta a ser pesquisada posteriormente: Os urbanistas brasileiros têm dado atenção necessária ao conteúdo normativo previsto no $\$ 1^{\circ}$ do Art. 40 do Estatuto da Cidade (BRASIL, 2001)?

Derradeiramente, o questionário aplicado com os urbanistas trouxe ainda a seguinte indagação: "Em vossa opinião, se as municipalidades adotarem um paradigma de planejamento municipal que integre plenamente todas as leis orçamentário-financeiras (PPA, LDO e a LOA) às diretrizes e priori- 
dades contidas no plano diretor municipal, implicará no aperfeiçoamento e na efetividade da política urbana?" Segue o gráfico demonstrando o entendimento dos urbanistas brasileiros.

Gráfico 6: Potencial efetividade da política urbana

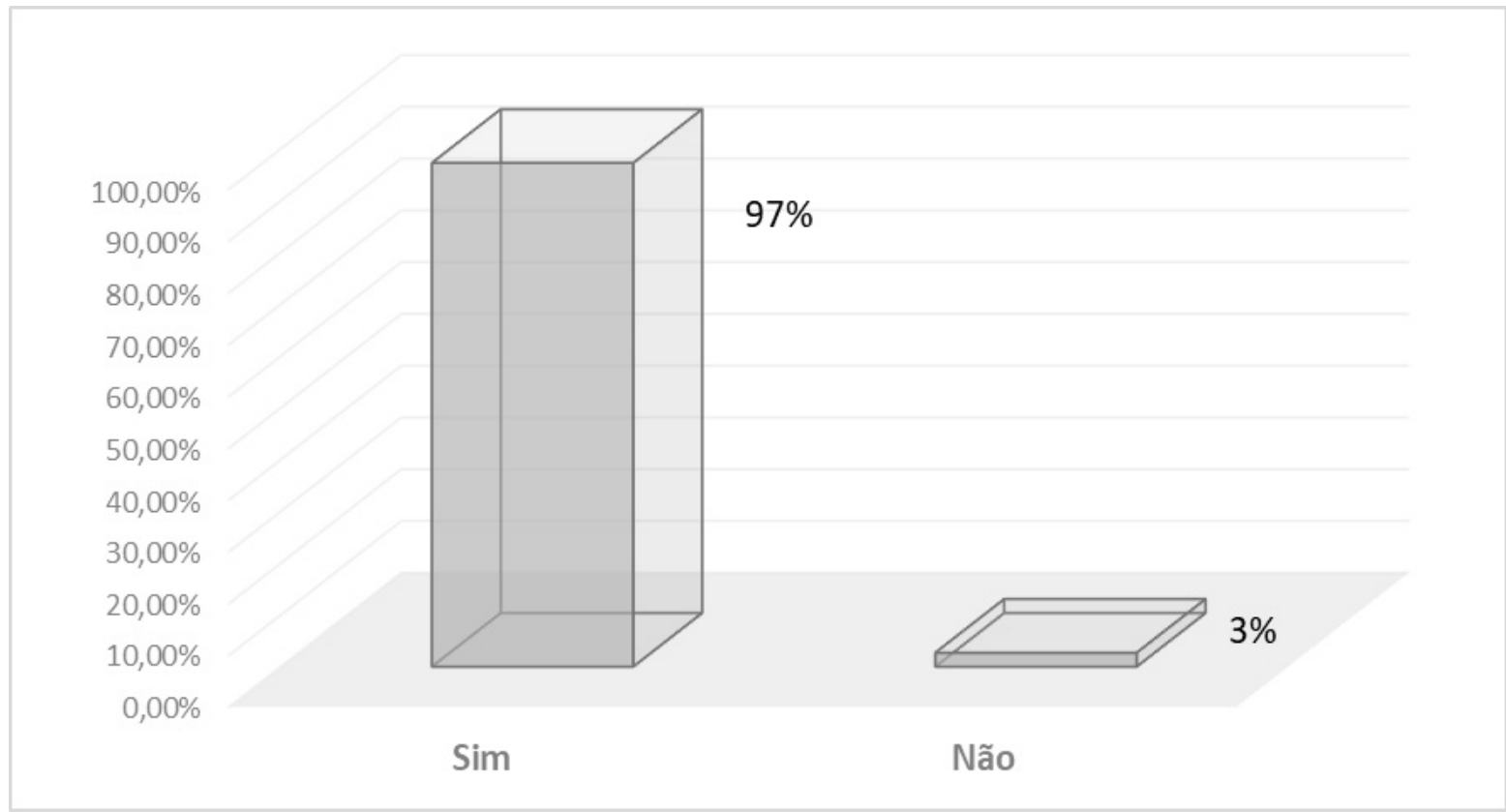

Fonte: Elaborado pelo autor

Constatamos que dos 37 (trinta e sete) urbanistas que responderam o segundo questionário, apenas 1 (um) entende que a aplicação de um modelo de planejamento municipal integral não repercutirá na execução de uma política urbana na qual os instrumentos urbanísticos e todos as políticas setoriais sejam efetivamente realizadas. Todos os demais, comungam com aquilo que outrora já foi exposto no referencial teórico, ou seja, que a integração das prioridades e as diretrizes fixadas no plano diretor com as previsões de receita pública e as autorizações para realização de despesas relativas à política urbana, implicará na efetividade de um novo paradigma, conforme ensina Santos (2014), um modelo cívico-territorial, no qual a organização e a gestão do espaço das cidades são instrumentos que auxiliam na adoção de política redistributiva que finde por diminuir as desigualdades sociais, econômicas e socioespaciais.

Desse modo, transcrevemos o trecho seguinte da obra de Santos (2014) que ensina que ao "modelo cívico territorial estariam subordinados todos os demais, a começar pelo próprio modelo econômico, que, no Brasil moderno, tanto anterior à Nova República como agora, tiraniza os demais" (SANTOS, 2014), pois este entendimento se comunica com a ideia exposta neste artigo, neste caso, que ao plano diretor (cívico) deverão estar ligadas e condicionadas as previsões normativas contidas nas demais leis de planejamento municipal (PPA, LDO e LOA).

\section{CONSIDERAÇÕES FINAIS}

Passados 20 anos do advento do Estatuto da Cidade (BRASIL, 2001), todos devem celebrar a data, sobretudo, aqueles que estão vinculados de modo, direto ou indireto, às temáticas inerentes à política urbana brasileira. Tal sentimento é justificado porque ocorreram avanços importantes que nos autoriza 
a falar em antes de depois do Estatuto da Cidade (BRASIL, 2001), tão evidentes foram as mudanças na lógica de planejamento do desenvolvimento das cidades.

Ampliou-se fortemente a institucionalização da política urbana, aumentando a presença de profissionais de distintas formações nas equipes que elaboram e gerem tal política pública, bem como, aprofundou-se o grau de participação da sociedade no processo de construção do planejamento do desenvolvimento urbano, alterações fundamentais na construção de uma política pública que precisa ser observada por diferentes primas.

Infelizmente, é necessário que os avanços mencionados sejam garantidos e novas conquistas sejam galgadas na política urbana. E uma das mais importantes diz respeito à concretização, ou seja, a efetividade dos diferentes planos setoriais existentes, assim como, a aplicação de todas as ferramentas (instrumentos) urbanísticas existentes na consolidada ordem urbana. Destarte, adotamos como hipótese de pesquisa que implementação de um planejamento municipal integral será capaz de aperfeiçoar a construção e a execução da política de desenvolvimento municipal, gerando, consequentemente, a efetividade dos instrumentos urbanísticos e das políticas setoriais urbanas.

Assim, visando enfrentar a hipótese construída, a pesquisa elegeu alguns objetivos para, ao final, responder ao problema de pesquisa que trataremos logo a seguir.

Sobre tais objetivos, anunciamos que todos foram alcançados. Portanto, contextualizamos a evolução da política urbana no Brasil, demonstramos a importância das leis orçamentário-financeiras no âmbito do planejamento municipal, bem como, identificamos a visão preponderante dos urbanistas brasileiros sobre a obrigatória integração das leis orçamentário-financeiras com as diretrizes e prioridades contidas nas leis dos planos diretores.

Uma conclusão importante desta pesquisa diz respeito ao papel exercido pelas cortes de contas públicas, pois tanto o primeiro quanto o segundo questionário (gráficos 2 e 5 ), evidenciaram que ainda é pequeno o percentual de tribunais de contas que já incorporaram em suas rotinas, fiscalizações acerca do cumprimento previsto no $\$ 1^{\circ}$ do Art. 40 do Estatuto da Cidade (BRASIL, 2001).

Em relação ao problema de pesquisa, podemos dizer que após terem sido alcançados os objetivos, sobretudo, após a análise dos dados obtidos pelos questionários eletrônicos, podemos afirmar com alto grau de certeza que os urbanistas brasileiros, em quase sua unanimidade (gráfico 6), entendem que a implementação de um modelo de planejamento municipal integral (harmonização das leis orçamentárias às diretrizes e prioridades previstas no plano diretor) gerará um aperfeiçoamento na execução da política urbana e, por conseguinte, no aumento do grau de efetividade dos instrumentos e políticas setoriais de natureza urbanística que, ao cabo, auxiliará na reconfiguração dos espaços das urbes de modo que as mesmas sejam verdadeiramente sustentáveis, plurais, equitativas, justas e o direito à cidade seja a todos ofertado.

Por fim, esperamos que o esforço realizado para obter as informações, analisá-las e responder ao problema de pesquisa sejam úteis a posteriores pesquisa sobre o mesmo objeto, qual seja, a efetividade da política urbana e a influência da adoção de um paradigma de planejamento municipal integral. 


\section{REFERÊNCIAS}

BASTOS, Celso Ribeiro. Curso de direito financeiro e tributário. 9a edição. São Paulo: Celso Bastos Editor, 2002.

BRASIL. Constituição da República Federativa do Brasil (1988). http://www.planalto.gov.br/ccivil_03/ Constituicao/Constituicao.htm Acesso em: 24 ago 2021.

BRASIL. Lei no 10.257/2001. Estatuto da Cidade. Disponível em:http://www.planalto.gov.br/ccivil_03/ leis/leis_2001/l10257.htm. Acesso em: 28 ago. 2021

BRASIL. Estimativas de população. Ano de 2001. Disponível em:https://www.ibge.gov.br/estatisticas/sociais/populacao/9103-estimativas-de-populacao.html?edicao=17283et=downloads. Acesso em: 28 ago 2021.

BRASIL. Estimativas de população. Ano de 2015. Disponível em:https://www.ibge.gov.br/estatisticas/sociais/populacao/9103-estimativas-de-populacao.html?edicao=17283\&t=downloads. Acesso em: 28 ago 2021 BRASIL. Perfil dos municípios brasileiros: 2018 / IBGE, Coordenação de População e Indicadores Sociais. - Rio de Janeiro: IBGE, 2019

BRASIL. Estimativas de população. Ano de 2020. Disponível em:https://www.ibge.gov.br/estatisticas/sociais/populacao/9103-estimativas-de-populacao.html?edicao=17283\&t=downloads. Acesso em: 28 ago 2021 CARRAZA, Roque Antonio. Curso de direito constitucional tributário. $9^{a}$ edição. São Paulo: Malheiros, 1997

CONCEIÇÃO, Antonio Cesar Lima da. Controle Social da Administração Pública: Informação \& Conhecimento - interação necessária para a efetiva participação popular nos orçamentos públicos. Monografia (2010). Especialização em Orçamentos Públicos do Instituto Serzedello Corrêa (ISC/DF).

ELALI, André. O federalismo fiscal brasileiro e o sistema tributário nacional. São Paulo: MP Editora, 2005.

MARICATO, Ermínia. As ideias fora do lugar, e o lugar fora das ideias. In: ARANTES, Otília Beatriz Fiori; VAINER, Carlos; MARICATO, Ermínia. A cidade do pensamento único. Desmanchando consensos. Coleção Zero à esquerda, Petrópolis, Vozes, 2013.

MELO, Rafael Tachini de. O plano diretor como instrumento de accountability democrática e sua observância no orçamento municipal. Dissertação de Mestrado. Universidade de Santa Catarina, Centro de Ciências da Administração e Socioeconômicas - ESAG, Florianópolis, 2020.

OLIVEIRA, Regis Fernandes de. Curso de direito financeiro. $2^{a}$ edição. São Paulo: Revista dos Tribunais, 2008.

SANTOS, Milton. O espaço do cidadão. São Paulo: Edusp, 2014.

SAULE, Nelson; UZZO, Karina. A trajetória da reforma urbana no Brasil. [s.l.]: [s.d.]. Disponível em:http://www.redbcm.com.br/arquivos/Bibliografia/a\%20trajectoria\%20n\%20saule\%20k\%20uzzo.pdf. Acesso em 25 ago 2021. 